\title{
Optimized Design of Dynamic and Real-Time Cash Flow Statement Interface on Mobile Terminal
}

\author{
Li Hongxia ${ }^{1, *}$ Liu Chang ${ }^{2}$
}

\author{
${ }^{1}$ Xi'an University of Science and Technology \\ ${ }^{2} X i^{\prime}$ an University of Science and Technology \\ *Corresponding author: Liu Chang. Email: 531704487@qq.com
}

\begin{abstract}
With the rapid development of the information technology era, mobile apps with different functions continue to emerge. In early 2020, affected by the new crown pneumonia epidemic, the number of users who use mobile apps to work online has also increased significantly. This requires that the interface design of mobile apps should be closer to user needs and focus on user experience.This article aims to optimize the cash flow statement attached table that can reflect the cash flow trends generated in the business activities, investment activities, and financing activities of the company. The data and information can assist the management of the company to discover, analyze, and solve problems in a timely manner, and then make Scientific and reasonable business decisions that are conducive to the development of the enterprise will advance its management functions from "after the event" to "in the event."And through the analysis of eye movement trajectories, hot spots and eye movement experimental data, considering that the information users of the cash flow statement are mainly business managers, there must be differences between professional and non-professionals. The results obtained after the experiment are try to browse the original report is quite different, and the dynamic real-time cash flow statement on the mobile terminal is more inclusive.
\end{abstract}

Keywords: Mobile, cash flow statement, Dynamic real-time, Interface optimization, Eye movement experiment

\section{INTRODUCTION}

As society enters the era of information technology, the development and application of smart phones has become an indispensable part of our lives. Mobile apps with different functions are constantly being produced with the development of smart phones, which virtually requires the interface of mobile apps The design should be closer to user needs and focus on user experience in order to stand out from the crowd in many apps. At the beginning of 2020, affected by the new crown pneumonia epidemic, the user scale of most network applications has increased significantly.In network applications, the user scale of online government affairs, online education, online payment, instant messaging, search engines and other applications has grown rapidly, with an increase of more than $10 \%$ compared with the end of 2018. It can be seen that the use of mobile APP for online office is moving towards normalization. Mobile reading is an efficient, time-saving, time- and space-saving way of obtaining information, which is widely popular in fast-paced life, and will gradually become popular in the accounting field. Many stock investment applications have been used in addition to the PC side. Display accounting information such as financial statements and financial statement analysis on mobile APP platforms, such as Oriental Wealth App, Tonghuashun APP, and Sina Finance APP. This application allows financial statements to be easily viewed on the mobile terminal, while ensuring the quality and timeliness of the information.However, the advent of this era may not bring more convenience for corporate management personnel to effectively extract financial statement information, but on the contrary, the requirements for accounting professionalism and accounting behavior of corporate management personnel have greatly increased. As the main information users of the cash flow statement-corporate managers, most of them do not have accounting background knowledge, and the cash flow statement reflects the cash flow generated in business activities, investment activities, and financing activities. Data information plays an important role in timely discovering, analyzing and solving problems for 
corporate management. Can corporate management use real-time and effective cash flow statement data to conduct timely analysis, and then make scientific and reasonable decisions that are conducive to corporate development? Business decisions are particularly important.

Therefore, the purpose of this experiment is to study the "mobile terminal dynamic real-time cash flow statement" that brings convenience in time and space for corporate management personnel to access statements. The real-time nature of the cash flow statement is not only reflected in shortening the preparation cycle, but also in The cash flow statement can be used in real time anytime, anywhere. Increase the availability of cash flow statements, users can analyze data in real time, and then make reasonable business decisions, effectively reducing business risks.

\section{LITERATURE REVIEW AND EXPERIMENTAL HYPOTHESIS}

\subsection{Research on Timeliness of Accounting Information}

Foreign researchers attach great importance to the timeliness of information. As early as 1982, Givoly and Palmon $^{[1]}$ studied the timeliness of annual accounting reports from the following aspects: the relationship between timeliness, accounting annual report types and company attributes, accounting annual report disclosures The industry' $\mathrm{s}$ time characteristics and timeliness of information content inspection, etc., believe that timeliness is an important attribute of relevance, which determines the usefulness of accounting information to a certain extent. The research of Kross and Schroeder (1984) ${ }^{[2]}$ found that the time lag of listed companies' financial reports is significantly related to company performance. In addition, companies with poor performance will postpone information disclosure, and companies with better performance will disclose information earlier. Trigo A, Belfo F, Estébanez R P (2014) ${ }^{[3]}$ research shows that compared with regular periodic reports, real-time reporting in accounting or simple real-time accounting has many advantages. However, rapid changes in the market and society have caused such periodic reports to become obsolete. However, the FASB believes that "timeliness is a subsidiary aspect of relevance. Although the relevance of information is not obtained only because of its timeliness, if there is no timeliness, the relevant information that the information should have cannot be obtained." Domestic scholars are right. Timeliness is also emphasized. Jiashu Ge and Feng Liu (2003) [4] proposed in the financial accounting conceptual structure system that the quality of accounting information is a "bridge" between accounting goals and the means to achieve them. The information provided serves as a constraint to enable it to meet the requirements of the target. Shengzhu $\mathrm{Wu}$ (2006) studied the annual report data of my country's listed companies from 1993 to 2003 and found that corporate performance is significantly positively correlated with the timeliness of annual report disclosure. The research of Zheng Sun and Shizhong Yang (2005) [5] also reached a similar conclusion. Therefore, different scholars hold different attitudes to the importance of timeliness, but they all regard timeliness as a key factor and pay greater attention to them.

\subsection{Research on real-time accounting control in the Internet environment}

Foreign scholars earlier proposed that an accounting information system that provides information analysis should be established in accordance with the requirements of the times. Since the 1980s, people in the accounting industry have questioned the accounting system at that time, such as: Howard Armitage ${ }^{[6]}$ Put forward: "In the entire accounting work process, the most critical department is still the control of the accounting information system. Research in this area is very important." Dawu Y, Ruijun Z (2003) ${ }^{[7]}$ said that corporate management has changed from Traditional management has turned to information and value management. On the one hand, this innovation challenges traditional accounting control, and on the other hand, it provides opportunities for the development of accounting control theory. At the same time, more and more companies are paying attention to a new accounting control theory, that is, accounting real-time control theory. This has further promoted the development of accounting control theory. The ERP system is recognized as "a fully integrated information system, that is, through a real-time common database to integrate the business between different departments of the company, the company's resource management, etc., to make it into a whole, so that the company can achieve each other Communication, collaboration, and integration between people."Edward (2003) ${ }^{[8]}$ and others have put forward the above views. This requires real-time database integration and effective use of resources, for example: blockchain technology is applied to the field of corporate financial management. Domestic research also emphasizes real-time control of corporate accounting information, such as the birth of a financial sharing platform. Professor Yan Dawu, Yang Jiwan and others put forward the "Accounting Management Activity Theory" in 1980. This is a point of view obtained through in-depth research and analysis on the basis of research on the accounting theory of Western countries, expounding the accounting control Function, to upgrade control from "supervision view" to "cybernetics", so as to achieve a high degree of realtime integration. Xiaoqian Wei (2019) ${ }^{[9]}$ believes that although Internet technology can speed up the 
effectiveness of information transmission, the ERP system still cannot guarantee the effectiveness of information transmission during the use process. In this regard, Yamin Liu(2019) ${ }^{[10]}$ proposed strategies to help promote the effectiveness of ERP. If an enterprise wants to give full play to the effectiveness of the ERP system, it should pay attention to creating a complete ERP management system and regularly optimize it. To ensure that it can play its role well, it has a positive impact on improving the enthusiasm of employees in relevant departments and guiding them to clarify their responsibilities and obligations, which helps to ensure the timely and accurate input of corporate information and the scientific allocation of various resources.

\subsection{Research on interface optimization}

The concept of interface design was first put forward by Western countries. It has achieved some results on the relationship between interface design and user experience, and has existed for a long time, forming a certain theory and system. In 1996, the development of CNC system was taken as an example.Fuchs-Frohnhofen ${ }^{[11]}$ and others put forward the point of view that the design of the human-computer interaction interface should match the user's cognitive style through the analysis of the user's thinking model in the work process. Ivory ${ }^{[12]}$. proposed in 2001 that the evaluation of usability is an important part in the user interface design process, and proposed an automated usability evaluation method. Constantine summarized a series of available user interface design guidelines in 2003. The structural principle is considered to be one of the most basic principles for guiding the layout of the user interface. Nachreiner ${ }^{[13]}$. studied the human factor in the process control system in 2006. After analyzing the interactive interface design case, they proposed that if the human factor design criterion is not fully considered, it will be allowed to operate. The mental workload of the person increases. Luo ${ }^{[14]}$. proposed an automatic user interface layout method for ontologybased reconfigurable systems based on the structural principles of the available user interface design guidelines in 2009. The theoretical application of their web interface design and the unique design method in web interface design have matured.Compared with foreign countries, domestic research and practice in the field of user experience started late. In April 2004, "UPA China" was established, and concepts such as user experience, usability, and interaction design were vigorously promoted in China. With UPA's first international conference in China in 2004, it should be the first time that the concept of Usability was introduced to the media. Both in theory and methodology are lagging behind foreign countries, but with the gradual increase in social awareness of "human-computer interaction interface" design, more and more people are studying interface design, especially mobile client interface design. The concept of availability and usability has gradually gained attention in various industries and fields in China. Wenjun Hou $(2014)^{[15]}$ stated that the mobile phone screen is limited by the size, and the content displayed to the user in the mobile phone interface must be more concise and effective. This requires the designer to effectively organize the information and display it to the user through a reasonable interface layout. content. Huimin Yan $(2018)^{[16]}$ In order to design an APP interface that can better meet the needs of users, through eye movement experiments, the pros and cons of shopping mobile APP interface design are evaluated from an objective perspective.

In summary, many scholars have emphasized the importance of cash flow statements and real-time control of accounting information for accounting work from different aspects, but how to combine cash flow statements with dynamic real-time in the actual accounting operation process? To avoid the time lag of information for the users of the cash flow statement, research on how to use the cash flow statement to make reasonable and effective decisions and how to apply the mobile client interface design to the field of accounting management is scarce. In view of this, the main purpose of this paper is to test whether the presentation of the dynamic and real-time cash flow statement on the mobile terminal will affect the enterprise management personnel's access to statement information. Based on this, the experimental hypothesis is put forward: when the information user browses the two cash flow statement pages, the page settings of the dynamic realtime cash flow statement will significantly affect the subjects' visual search behavior.

\section{EXPERIMENT PROCEDURE}

\subsection{Participants}

This article selects 25 university graduate students aged 20-29 years as the testers for this experiment. Among them, 11 subjects have a background in management professional knowledge, and the other 14 subjects have a background in accounting professional knowledge and have used mobile phones. I have browsed the cash flow statement at the end. The subjects' uncorrected vision or corrected strength were above 1.0, and there were no eye diseases such as color blindness or color weakness, and none of the subjects had participated in such experiments. After the experiment, 5 unqualified eye movement data were screened out. In this experiment, 20 valid data were finally analyzed. There were 10 people in the experimental group and the control group. 


\subsection{Stimulus material selection}

The stimulus material for this experiment selects screenshots of the Oriental Wealth APP page that is currently known to people, various websites or professional data statistics centers, and the optimized mobile terminal dynamic real-time cash flow table, using direct screenshots as The experimental material is to achieve a realistic browsing state, as shown in Figure 1 and Figure 2. In order to truly study the status of people browsing the mobile cash flow statement, so that the audience can quickly and intuitively feel the information. Import the Figures into the eye tracker separately.

\subsection{Experimental equipment}

This eye movement test experiment uses the Tobii Pro Spectrumy eye tracker, which is a brand new and advanced eye tracking platform designed for human behavior research and rapid eye movement behavior research. The device can collect data at a sampling rate of $600 \mathrm{~Hz}$, while allowing subjects to move their heads freely. It opens up new possibilities for many research fields, such as psychology, developmental research, neuroscience, reading research, and ophthalmological research. Tobii Pro Spectrum eye tracking system uses Tobii's advanced eye tracking algorithm, sophisticated hardware design and high-quality components to ensure data quality and reproducibility. With its large space for the subject's head movement, it can realize eye tracking studies for children and other subjects who require jaw rest to be fixed to restrict movement under normal circumstances. Very high tolerance for fast and large head movements.Participants' eye tracking beyond entering the tracking range can immediately restore reliable data quality.

\subsection{Experimental process}

This experiment uses two kinds of reports, the existing mobile cash flow statement, the optimized dynamic real-time cash flow statement as stimulus materials for the experiment. During the entire experiment, in order to avoid the previous Figure from affecting the next Figure, the experiment Figures were played in random arrangement.This experiment was carried out in an indoor environment where the lighting and sound have been controlled. The experiment process is as follows:

First, bring the subjects into the laboratory to familiarize themselves with the experimental environment, and inform them of the experimental process and specific matters.

Second, ask the subject to sit in front of the eye tracker, control the distance between the subject' s eyes and the center of the screen to be $600-700 \mathrm{~mm}$, adjust the sitting posture, and perform a five-point calibration.

Third, the examiner used simple and easy-tounderstand language to present the instructions to the participants. The instruction is: Welcome to participate in this eye movement experiment. This experiment will show you a few screenshots of the mobile cash flow table interface on the computer screen. Please browse the Figures according to your daily browsing habits. Please do not move during the experiment. Head, in this experiment, subjects press the space bar to play the Figure autonomously.

Fourth, start the pre-experiment after the instruction is over. Participants are required to lead the test screen, and a mobile cash flow table page will appear on the screen for participants to watch, so that the participants can become familiar with the experiment procedures. After the participants are familiar with the experiment process, the lead examinees remind the participants to start the formal experiment.

Fifth, the formal experiment begins. After the formal experiment begins, please take the whole process seriously, browse with real browsing habits, and record the subject's eye movement data. Participants are required to carry out the experiment according to the instruction:

Step1: Guidance text appears on the screen: Please browse the screenshot of the cash flow statement on the mobile terminal and find "Net cash flow from fundraising activities";

Step2: Guidance text appears on the screen: Please browse the screenshot of the optimized cash flow statement and find the "net increase in cash and cash equivalents" (or other) item;

Step3: The experiment is over, thank you for participating in the experiment!

Sixth, the experiment is over.

Precautions during the experiment: The subject is required to mute or shut down the mobile phone after entering the laboratory, and conversation is prohibited. Participants must face up to the seriousness of the experiment, and the test leader announces the end of the experiment before the whole experiment ends.

\section{DATA ANALYSIS}

\subsection{Experimental data analysis}

\subsubsection{Attention to the dynamic and real-time cash flow statement of the mobile terminal}

Divide the interest area of the stimulus material Figure 1 and Figure 2 into three areas: A, B and a, b, and $\mathrm{c}$. The content of the A, a interest area report, the B 
and $b$ interest areas as the search target area, and the interest area $c$ browse percentage area. As

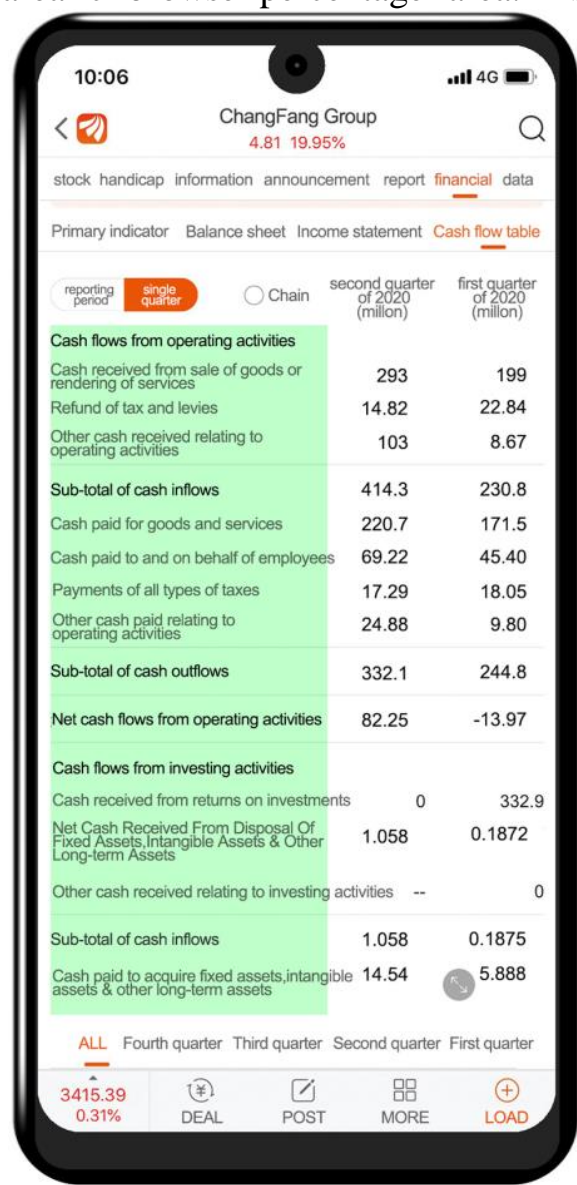

shown in Figure 1 and Figure 2 respectively.

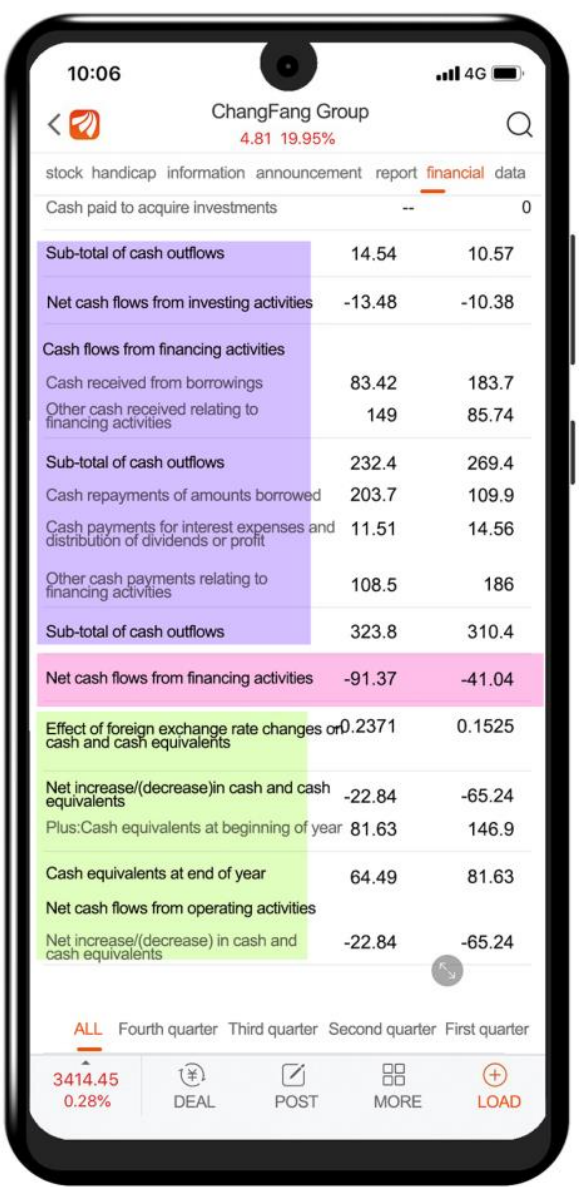

Figure 1. The AOI of the interface of the mobilecash flow statement

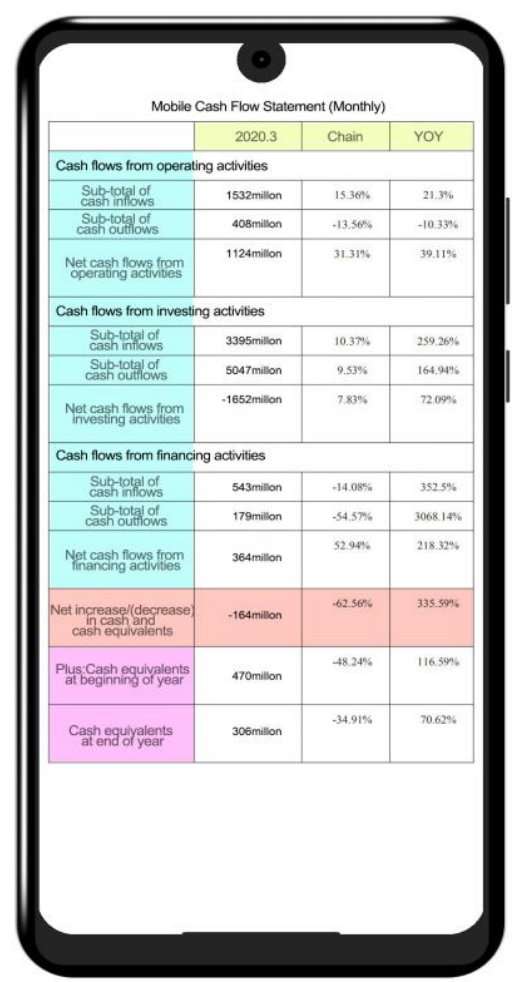

Figure 2. the AOI of Mobile terminal dynamic real-time cash flow statement 
The AOI of the area of interest of Figure 1 and Figure 2 is divided into Figure 1and Figure 2. The task of setting up this task is mainly to analyze the participant's attention to the dynamic real-time cash flow statement. Figure 1 and Figure 2 are shown in Table 1 for the collation of experimental data for completing tasks.

Table 1. Data of eye movement experiment

\begin{tabular}{c|c|c|c|c}
\hline Project & AOI-A & AOI-B & AOI-a & AOI-b \\
\hline $\begin{array}{c}\text { The number of people } \\
\text { concerned about AOI }\end{array}$ & $100 \%$ & $100 \%$ & $100 \%$ & $100 \%$ \\
\hline First entry time & 2.39 & 8.18 & 1.46 & 5.38 \\
\hline Number of fixations & 36.77 & 9.86 & 17.32 & 13.05 \\
\hline Total fixation time & 9.47 & 2.86 & 4.72 & 4.50 \\
\hline
\end{tabular}

It can be seen from the data that the number of people who followed the AOI in Figure 1 and Figure 2 is $100 \%$, and all the subjects are concerned about the content of the report and the target AOI. The time it takes for the line of sight to enter the target AOI for the first time in Figure 2 is relatively short, and the path analysis diagram of the subjects can analyze this point, as shown in Figure 3and Figure 4.
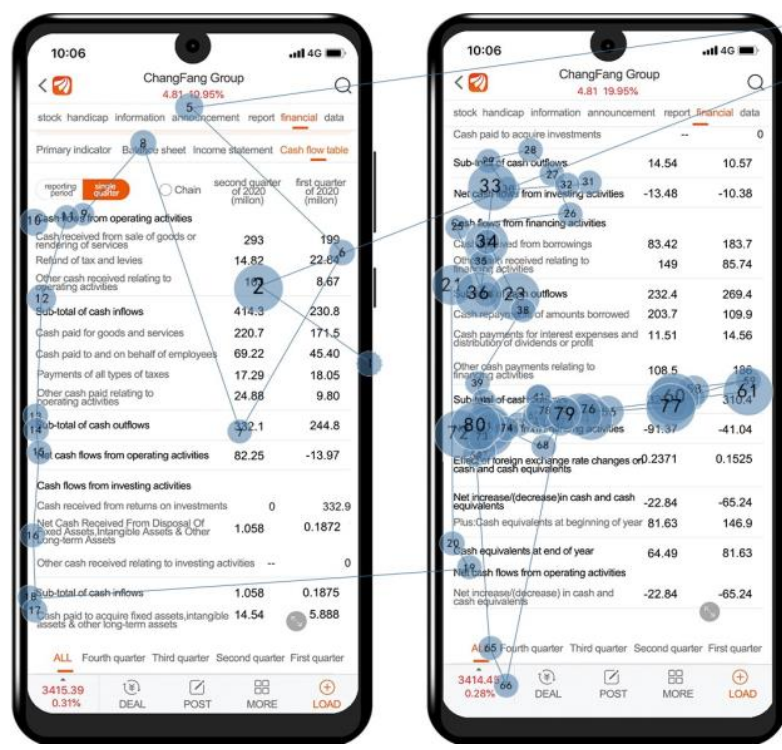

Figure 3. Track chart of mobile cash flow statement

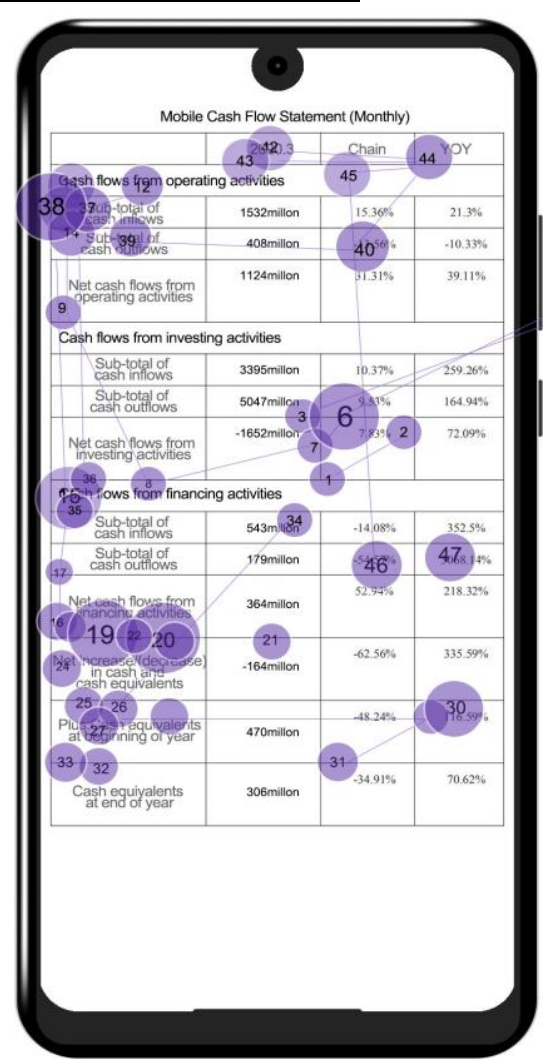

Figure 4. Dynamic real-time cash flow statement gaze trajectory diagram

Figures 3 and 4 are two scan path diagrams randomly selected from the subjects, both of which are completed by the subject with a search target. By observing the two pictures, it can be seen that the subject' $s$ line of sight path is from Start in the middle of the picture, then move to the top of the picture, then move to AOI-A, browse from top to bottom, first left and then right, and enter AOI-B when you get closer. The study found that 20 subjects with search targets observed the two cash flow tables and recorded the eye tracking path. Generally speaking, when there are search targets, the overall path also shows a vertical browsing pattern. It shows that the interface design of the two 
cash flow statements meets the information user's distribution theory of interface browsing.

The average number of fixation points in the target AOI and the average fixation time of the target AOI can be reflected by a heat map. As shown in Figure 5,Figure 6 . Figures 5 and 6 are the sum of the heat maps of the 20 subjects in Figure 1and Figure 2 respectively. It can be seen that the subjects pay more attention to the dynamic real-time cash flow statement. The gaze in the target AOI in Figure 2 The number of points is dense, and the total gaze time of the target AOI is longer, showing the deepest red.
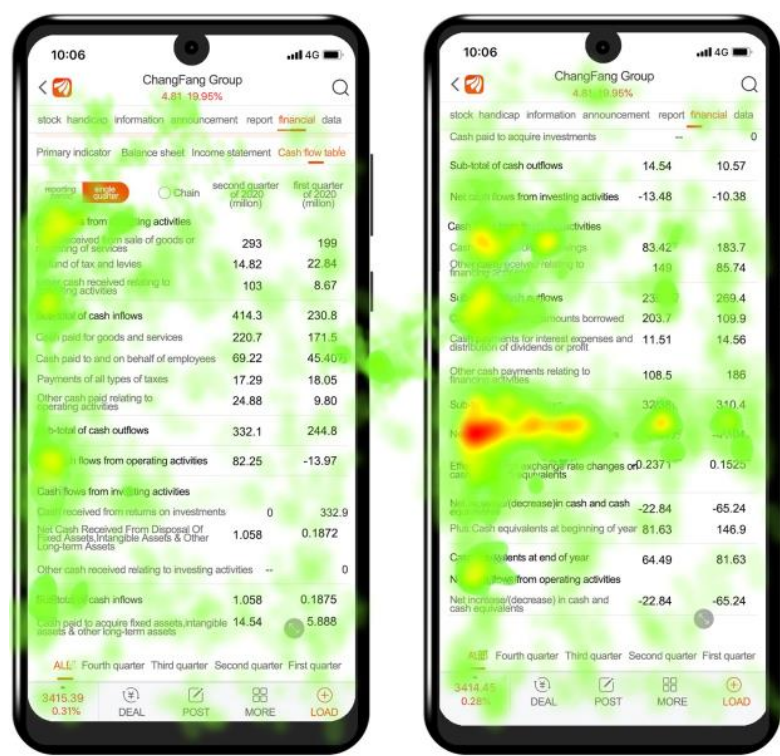

Figure 5. Heat map of mobile cash flow meter

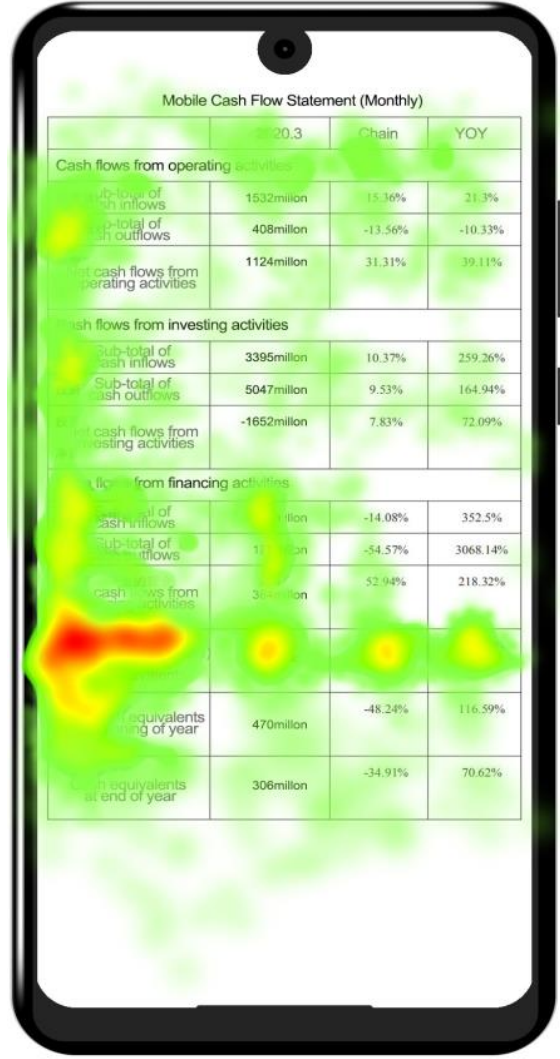

Figure 6. Heat map of dynamic real-time cash flow statement on mobile terminal

From the above data analysis, it can be seen that the participants have a higher degree of attention to the dynamic real-time cash flow statement (Figure 2), the first entry time is shorter, and the time of attention is longer, and the number of attention points is larger. The above analysis is only through intuitive and simple comparison of pictures, but also requires quantitative research and analysis of eye movement data by statistical methods in order to draw more accurate and scientific conclusions.

\subsubsection{Eye tracking data output analysis}

\subsubsection{First entry time}

The first entry time indicates the degree of perception, which means the time from when the stimulus material is presented to the time before the subject's gaze point appears in the area of interest. The first entry time is the time from the moment the subject's sight touches the picture of the cash flow statement to the time when the subject perceives the target point, that is, the sensitivity of the subject's visual perception. The first entry time of each level is shown in Table 2, and the t-test results are as follows. 
Table 2. Data of eye movement experiment

\begin{tabular}{l|c|r|r|r|r|r|r|r|r}
\hline & Number of people & \multicolumn{2}{|c|}{ A } & \multicolumn{2}{c|}{$\mathrm{a}$} & \multicolumn{3}{c|}{ B } \\
\hline & & $\mathrm{M}$ & SD & $\mathrm{M}$ & $\mathrm{SD}$ & $\mathrm{M}$ & $\mathrm{SD}$ & $\mathrm{M}$ & $\mathrm{SD}$ \\
\hline $\mathrm{Np}$ & 10 & 0.227 & 0.216 & 0.306 & 0.188 & 0.205 & 0.142 & 0.29 & 0.186 \\
$\mathrm{p}$ & 10 & 0.253 & 0.121 & 0.336 & 0.265 & 0.252 & 0.111 & 0.293 & 0.171 \\
Total & 20 & 0.243 & 0.162 & 0.2332 & 0.123 & 0.324 & 0.232 & 0.292 & 0.173 \\
\hline
\end{tabular}

An independent sample t-test analysis of the time of first entry showed that the difference in the subjects' gaze at the interest area $\mathrm{A}$ was not significant: $\mathrm{t}=-1.280$, $\mathrm{p}=0.409$; the difference in the interest area $\mathrm{B}$ was significant: $t=-0.333, p=0.041$, the NP individual gazes for the first time The time is significantly longer than the $\mathrm{P}$ individual; $\mathrm{a}$ is not significant in the region of interest: $\mathrm{t}=-0.616, \mathrm{p}=0.688 ; \mathrm{b}$ is not significant in the region: $\mathrm{t}=-0.346, \mathrm{p}=0.426, \mathrm{NP}$ represents nonprofessional individuals and $\mathrm{P}$ represents professional individuals.

A paired-sample t-test on the first entry time found that the two pictures A and a are significantly different. The first fixation time margin of $\mathrm{A}$ is significantly greater than a, $\mathrm{t}=1.86, \mathrm{p}=0.077$; the first fixation time of $\mathrm{B}$ is significantly greater than $\mathrm{b}, \mathrm{t}=2.523, \mathrm{p}=0.020$.

Eye tracking experiment data shows that professional and non-professional subjects noticed the same time when browsing the original cash flow statement for the first time in area A, and the first time they entered the target search area B for nonprofessional time was longer than professional; browsing the new cash flow statement When I first noticed that the time difference in area $\mathrm{a}$ is not significant, and the difference in browsing area $b$ is not significant, it is obvious that the new financial statements are more friendly to non-professional individuals. For the two reports, the first gaze time of the original report item is longer than that of the new report, indicating that the subject needs more time to enter the interest area, and it also shows that area a can get the subject's attention faster, and at the same time, enter the search target The time of B is also longer than that of $b$, which shows that $b$ can get more attention, and it also shows that the report where $b$ is located can more easily search for useful information.

\subsubsection{Duration of first fixation}

The first fixation duration indicates the degree of attention, which refers to the duration of the first fixation point that appears in the interest area. The first gaze time represents the time at which the cognitive process starts after perception, is the time to form the gaze and perform the first information processing, and is the process of initial recognition of the target in the area as a whole. Therefore, the first fixation time mainly indicates the degree to which the AOI attracts attention. The duration of the first fixation at each level is shown in Table 3, and the t-test results are as follows.

Table 3. Eye tracking data for first fixation duration

\begin{tabular}{l|c|c|c|c|c|c|c|c|c}
\hline & Number of people & \multicolumn{2}{|c|}{$\mathrm{A}$} & \multicolumn{2}{c|}{$\mathrm{a}$} & \multicolumn{2}{c|}{$\mathrm{B}$} & \multicolumn{2}{c}{$\mathrm{b}$} \\
\hline & & $\mathrm{M}$ & $\mathrm{SD}$ & $\mathrm{M}$ & $\mathrm{SD}$ & $\mathrm{M}$ & $\mathrm{SD}$ & $\mathrm{M}$ & $\mathrm{SD}$ \\
\hline $\mathrm{Np}$ & 10 & 1.758 & 1.660 & 1.303 & 0.928 & 7.737 & 7.028 & 5.123 & 3.585 \\
$\mathrm{p}$ & 10 & 2.830 & 2.090 & 1.564 & 1.005 & 8.492 & 3.564 & 5.550 & 2.215 \\
Total & 20 & 2.392 & 1.960 & 1.457 & 0.960 & 8.183 & 5.121 & 5.376 & 2.783 \\
\hline
\end{tabular}

The independent-sample t-test analysis of the duration of first fixation shows that the difference in $\mathrm{A}$ is not significant: $t=-0.362, p=0.515$; the difference in $B$ is not significant: $t=-0.867, p=0.521$; the difference in a is not significant: $t=-0.293, p=0.271$; single $b$ has no significant difference: $\mathrm{t}=-0.050, \mathrm{p}=0.851$.

A paired-sample t-test on the duration of the first fixation revealed that the $\mathrm{A}$ and a parts of the two pictures were not significantly different, $t=0.231$, $\mathrm{p}=0.820$. The difference between the two parts $\mathrm{B}$ and $\mathrm{b}$ is not significant, $\mathrm{t}=0.519, \mathrm{p}=0.609$.

The eye tracking data showed that when the subjects looked at the two reports for the first time, the degree of processing was the same. 


\subsubsection{Total fixation time}

The total gaze time refers to the total gaze time of the subject while staying in a certain area of interest, which can be obtained directly. This indicator reflects and measures how difficult the experimental materials are for users' perception or how attractive they are to users.

The total fixation time at each level is shown in Table 4, and the t-test results are as follows.

Table 4. Total fixation time eye movement data

\begin{tabular}{l|c|r|r|r|r|r|r|r|r}
\hline & Number of people & \multicolumn{2}{|c|}{ A } & \multicolumn{2}{|c|}{$\mathrm{a}$} & \multicolumn{2}{|c|}{$\mathrm{B}$} & \multicolumn{2}{c}{$\mathrm{b}$} \\
\hline $\mathrm{Np}$ & & $\mathrm{M}$ & $\mathrm{SD}$ & $\mathrm{M}$ & $\mathrm{SD}$ & $\mathrm{M}$ & $\mathrm{SD}$ & $\mathrm{M}$ & $\mathrm{SD}$ \\
\hline $\mathrm{p}$ & 10 & 11.197 & 6.008 & 4.737 & 2.955 & 2.551 & 2.427 & 2.949 & 1.691 \\
\hline Total & 10 & 8.279 & 2.324 & 4.708 & 1.683 & 3.071 & 2.818 & 5.573 & 4.467 \\
\hline
\end{tabular}

The independent-sample t-test analysis of total fixation time showed that the difference in $\mathrm{A}$ was significant: $t=1.600, p=0.015$, the total fixation time of $\mathrm{Np}$ individuals was significantly greater than that of $\mathrm{p}$ individuals; the difference in $\mathrm{B}$ was not significant: $\mathrm{t}=-$ 0.450, $\mathrm{p}=0.993$; a difference Significant: $\mathrm{t}=0.030$, $\mathrm{p}=0.034$, the total fixation time of $\mathrm{Np}$ individuals was significantly longer than that of $p$ individuals; $b$ margin of difference was significant: $t=-1.670, p=0.058$, the total fixation time of $\mathrm{Np}$ individuals was significantly less than that of $\mathrm{p}$ individuals.

A paired-sample t-test on the total fixation time found that the two parts A and a of the two pictures are significantly different. The total fixation time of $\mathrm{A}$ is significantly greater than $\mathrm{a}, \mathrm{t}=6.593, \mathrm{p}<0.001$; the total fixation time of $B$ is significantly less than $b, t=-2.778$, $\mathrm{p}=0.011$.

Eye tracking data shows that the total gaze time reflects and measures the difficulty of the experimental materials for the user's cognition, or the material's attractiveness to the user. The longer the gaze time, the greater the processing difficulty or the greater the attractiveness. In this study, There are significant differences between professional and non-professional individuals in browsing area A and a. Non-professional individuals have longer browsing time than professional individuals, indicating that non-professional individuals are more difficult to process information than professional, but a is shorter than A's total gaze time, indicating that area a is easier to process. However, there is no difference between the two groups of individuals in browsing area $\mathrm{B}$, indicating that there is no processing difference in the search target, but the total fixation time of $b$ is significant. At this time, professional individuals have a longer fixation time than non-professional individuals, which can predict that professional individuals are more interested in this place. Comparing the two reports, the total attention time of the original report items is longer than that of the new report, indicating that the original report items themselves are more than the new report items, which leads to more time-consuming information processing; and the total attention time for the search target of the original report is less than all the targets of the new report. It shows that the new report search target can attract the attention of the participants.

\subsubsection{Number of fixation points}

The number of gaze points in the interest represents the user's information processing of the target, and the larger the number, the more (but not necessarily useful) visual information the reader has processed. The experimental results of the number of fixation points are shown in Table 5, and the t-test results are as follows.

Table 5. Number of fixation points

\begin{tabular}{l|c|r|c|r|r|r|r|r|r}
\hline & Number of people & \multicolumn{2}{|c|}{ A } & \multicolumn{2}{c|}{ a } & \multicolumn{2}{|c|}{ B } & \multicolumn{2}{|c}{$\mathrm{b}$} \\
\hline & & $\mathrm{M}$ & SD & $\mathrm{M}$ & $\mathrm{SD}$ & $\mathrm{M}$ & $\mathrm{SD}$ & $\mathrm{M}$ & $\mathrm{SD}$ \\
\hline $\mathrm{Np}$ & 10 & 42.111 & 22.441 & 17.555 & 12.669 & 8.555 & 8.001 & 9.888 & 5.134 \\
$\mathrm{p}$ & 10 & 33.076 & 10.804 & 17.153 & 6.731 & 10.769 & 11.497 & 15.230 & 11.620 \\
Total & 20 & 36.772 & 16.710 & 17.318 & 9.331 & 9.863 & 10.058 & 13.045 & 9.717 \\
\hline
\end{tabular}


The independent-sample t-test analysis of the number of fixation points shows that the difference in $\mathrm{A}$ is significant: $t=1.264, p=0.021$, the number of fixation points in $\mathrm{np}$ individuals is significantly greater than that in $\mathrm{p}$ individuals; the difference in $\mathrm{B}$ is not significant: $\mathrm{t}=-0.498, \mathrm{p}=0.715$; $\mathrm{a}$ is not significant: $\mathrm{t}=0.734, \mathrm{p}=0.097$; $\mathrm{b}$ is not significant: $\mathrm{t}=-1.287, \mathrm{p}=0.07$.

The paired-sample t-test on the number of fixation points found that the two parts $\mathrm{A}$ and a of the two pictures are significantly different, and the number of fixation points of $\mathrm{A}$ is significantly greater than that of a $\mathrm{t}=7.54, \mathrm{p}<0.001$. The difference between the two parts $\mathrm{B}$ and $b$ is not significant, $t=-1.633, p=0.117$.

Eye tracking data shows that the more fixation points, the more difficult the current task, or the subjects are more interested in it. The eye tracking data analysis of this research shows that professional and nonprofessional individuals have a large difference in browsing area $\mathrm{A}$, indicating that area $\mathrm{A}$ is more difficult for non-professional individuals, and there is no difference in the difficulty and degree of interest in browsing B. Professional and non-professional individuals browse a, b. There is no difference, indicating that the professional level is not high for browsing these two areas, and both professional and non-professional can obtain information. The more fixation points in area $\mathrm{A}$ of the two reports means that the information in this area is more complicated and the subjects are more difficult. Therefore, streamlining the content of the report items can reduce the difficulty of the subjects' browsing.

\subsubsection{Percentage of gaze time in the area of interest}

The percentage of gaze time in the area of interest refers to the percentage of the participant' $s$ gaze time in different page areas to the total gaze time. The larger the ratio, it means that the area of interest is more likely to attract the attention of the subjects. The experimental results of the percentage of gaze time in the interest area are shown in Table 6, and the t-test results are as follows.

Table 6. Percentage of gaze time in the area of interest eye movement data

\begin{tabular}{c|c|c|c|c|}
\hline Number & \multicolumn{2}{|c|}{$\begin{array}{c}\text { Cash flow } \\
\text { statement }\end{array}$} & \multicolumn{2}{c|}{$\begin{array}{c}\text { Dynamic real-time } \\
\text { cash flow statement }\end{array}$} \\
\hline & $\mathrm{M}$ & $\mathrm{SD}$ & $\mathrm{M}$ & $\mathrm{SD}$ \\
\hline 20 & 0.793 & 0.135 & 0.703 & 0.147 \\
\hline
\end{tabular}

A paired-sample t-test analysis was performed on the percentage of gaze in the interest area, and the result found that the original report was significantly smaller than the new report, $\mathrm{t}=2.985, \mathrm{p}=0.007$.

In summary, the analysis of eye movement data shows that in the original mobile cash flow statement, the first time to look at is longer than the dynamic realtime cash flow statement form, indicating that it is easier for individuals to see the content of the dynamic real-time cash flow statement first. The analysis of the total gaze time and the number of gaze points shows that the total gaze time and the number of gaze points in area A of the original cash flow statement are significantly greater than part a of the dynamic real-time cash flow statement, indicating that when the report is split screen, the information The processing is difficult, and individuals will spend more time searching for the data they need. On the other hand, there is no significant difference in the eye tracking data of the two types of reports $\mathrm{B}$ and $\mathrm{b}$, which further shows that the report split screen is not necessary. It is not conducive to individuals to find target information, and it is not conducive to saving time. Professionals and nonprofessionals have significant differences in the eye movement data of the original cash flow statement, but for the browsing of the dynamic real-time cash flow statement, the difference between the two is not significant, indicating that the browsing of the dynamic real-time cash flow statement is not professional The capacity limitation is better than the original cash flow statement. Combined with the analysis of the AOI gaze ratio, it can also be found that the gaze efficiency of the dynamic real-time cash flow statement is higher and it is a better report form. Therefore, compared with the two forms of statements, the dynamic real-time cash flow statement is a better choice.

\subsection{Questionnaire analysis}

After the completion of each experiment, the author immediately conducted a questionnaire survey of 20 subjects. The survey questions involved the first impression of the dynamic real-time cash flow statement, the layout of the mobile cash flow statement, and the mobile cash flow statement reflecting the trend and realtime nature. , Availability and whether it can bring convenience to information users, trend graphs, etc. The results of the questionnaire analysis show that the results of the questionnaire are basically consistent with the data analysis of the eye tracker, and the dynamic real-time cash flow statement is more than the original cash flow statement. It is helpful for information users, especially management personnel, to browse the report information and verify the hypothesis. 
On the first impression of the dynamic real-time cash flow statement, $4.76 \%$ of the participants thought they were generally satisfied, and $95.24 \%$ of the participants thought they were satisfied or very satisfied. In the optimized layout of the mobile cash flow statement, $14.9 \%$ of the subjects were generally satisfied, $33.3 \%$ of the subjects were satisfied, and $52.38 \%$ of the subjects were very satisfied. In terms of real-time response, $57.14 \%$ of the subjects considered very satisfied, and $42.86 \%$ of the subjects considered satisfied or generally satisfied. In terms of their attitude towards the mobile terminal as a carrier, $71.43 \%$ of the subjects thought they were very satisfied, $19.05 \%$ said they were satisfied, and $9.52 \%$ said they were generally satisfied. $95.24 \%$ of the subjects agreed with the fact that the cash flow statement information presented on the same interface is highly readable. Regarding the optimized report as a supplementary form to provide useful information for information users, $100 \%$ of the subjects agreed.

\section{CONCLUSION}

In summary, through the analysis of eye movement experimental data, for the main information users of corporate financial statements, real-time statements that can reflect data trends to a certain extent are better than the original cash flow statement. The main information users of the table are business managers. Taking into account the inevitability of professional and nonprofessional differences, the result is that the dynamic real-time cash flow statement is more inclusive, while professional and non-professionals browse the original statement. big different. Compared with other research methods, we found that the data of eye movement research has more practical significance, and the factors that affect the efficiency of corporate management personnel in obtaining cash flow statement information are more clear. The specific influencing factors are: the reporting period, report items, the content of the statement,report carrier and percentage trend. We also collected the opinions of the subjects qualitatively in combination with questionnaires and other communication methods, and the results were consistent with the previous assumptions. The combination of multiple methods shows that the study of visual cognitive psychology can make our knowledge and understanding of human behavior deeper and more thorough. The main conclusions are as follows:

First, the dynamic real-time cash flow statement on the mobile terminal is more helpful for the enterprise managers to obtain the statement information in time than the original cash flow statement.

Second, there is a significant difference between the accounting professional and non-professional corporate management personnel in browsing the original mobile cash flow statement, and the difference in browsing the mobile terminal dynamic real-time cash flow statement is not significant, so the mobile terminal dynamic realtime cash flow statement is more Excellent form.

\section{REFERENCES}

[1] Givoly D. and Palmon D. The timeliness of annual earnings announcement: some empirical vidence [J]. The Accounting Review,1982,(7):486-508.

[2] Kross W. and Schroeder D. An empirical investigation of the effect of quarterly earnings announcement timing on stock returns[J].Journal of accounting Research,1984,(22):153-176.

[3] Trigo A, Belfo F, Estébanez R P. Accounting information systems: The challenge of the real-time reporting $[\mathrm{J}]$. Procedia Technology, 2014, 16: 118127.

[4] Jiashu Ge, Feng Liu. Accounting TheoryResearch on the Conceptual Structure of Financial Accounting[J].Beijing: China Financial and Economic Publishing House, 2003.

[5] Zheng Sun, Shizhong Yang. Accounting Standards Research Library: Quality Characteristics of Accounting Information[M]. Dalian: Dalian Publishing House, 2005: 179.

[6] H.Armitage, Canada, Linking Management Accounting System with Computer Technology[J], 1984,120-123.

[7] Dawu Y, Ruijun Z. A Research on Accounting Real-time Control[J]. Accounting Research, 2003, 4.

[8] EdwardM A. Duplage and MarizeAstani, Implementing ERP in manufacturing 、 information systems management[J],2003,49.

[9] Xiaoqian Wei. Research on the problems and countermeasures of ERP in the application of corporate accounting[J]. Management and Technology of Small and Medium-sized Enterprises (Mid-day Issue). 2019,12.

[10] Yamin Liu . On the influence of ERP on the accounting and financial management of Chinese enterprises[J]. Marketing industry. 2019,47.

[11] Fuchs-Frothnhofen P, Hartmann E A, Brandt D, et al. Designing Human-machine Interfaces to Match the User's Mental Models[J]. Control Engineering Practice, 1996,4(1):13-18.

[12] Ivory M Y, Hearst M A. The State of the Art in Automating Usability Evaluation of User Interfaces [J]. ACM Computing Surveys, 2001,33(4):470-516.

[13] Nachreiner F, Nickel P, Meyer I. Human Factors in Process Control Systems: The Design of Human- 
machine Interfaces[J]. Safety Science, 2006,44(1):5-26.

[14] S.Y. Luo, Y.L. Wang, J.M. Guo."Research on ontology-based usable user interface layout approach.'International Conference on Intelligent Computing and Intelligent Systems, 2009.

[15] Wenjun Hou , Yuan Qin. Research on typical mobile phone interface structure based on eye movement browsing rules[J]. Journal of Beijing University of Posts and Telecommunications. 2014, 16(01): 25-30.

[16] Huimin Yan , Junfeng Wang, Wenjun Wang . Analysis and evaluation of eye movement experiment on the interface design of shopping APP[J]. Industrial Design Research. 2018,11. 